\title{
Study of Breast Lump of 2246 Cases by Fine Needle Aspiration
}

\author{
Pradhan M, ${ }^{1}$ Dhakal HP2 \\ 'Pathology Clinic, Rikshospitalet-Radiumhospitalet Medical Center, Montebello, Norway, ${ }^{2}$ Department of Pathology, B P \\ Koirala Memorial Cancer Hospital, Bharatpur, Nepal
}

\section{ABSTRACT}

The purpose of this study was to analyze breast lesions causing breast lump with special reference to patients younger and older than 30 years of age diagnosed by fine-needle aspiration (FNA) and to evaluate the histology of the cases diagnosed as suspicious of malignancy in FNA.

All patients who underwent FNA during four years period (2000-2004) were included in this study. The FNA procedure was performed and interpreted by the experienced pathologists. Histological evaluation of the suspicious cases in FNA was done and was based on excisional biopsy or mastectomy specimen.

Out of 2246 FNA performed, 1840 were diagnosed as non-malignant, 6 atypical ductal hyperplasia, 52 suspicious of malignancy and 348 as malignant. The most common non-malignant lesions included 975 (43\%) fibroadenosis, 180 (8\%) fibroadenoma, $126(6 \%)$ abscess and 96 (4\%) fibrocystic changes. The patients were further divided into two groups: group I consisted of 918 patients aged 30 years and younger and group II consisted of 1328 patients above 30 years. In group I, 444 (48.4\%) were diagnosed as fibroadenosis and only 15 (1.6\%) cases were malignancies. In group II $531(40 \%)$ were fibroadenosis and $333(25 \%)$ were malignant. Patients more than 30 years old had significantly higher malignancy diagnoses $(\mathrm{P}<0.001)$. The odds of being diagnosed as malignant tumor among the higher age group patients (>30 years) is 21 times larger (confidence interval 12.4, 35.6) than the younger patients $(\leq 30$ years). In $63 \%(27 / 43)$ of the suspicious cases, malignancy was diagnosed in histological examination.

Cancer and Fibroadenosis are two most common causes of breast lumps in Nepal. Incidence of malignancy is significantly lower in patients aged 30 years and younger than in patients aged older than 30 years. Suspicious FNA cases should be evaluated histologically to rule out malignancy.

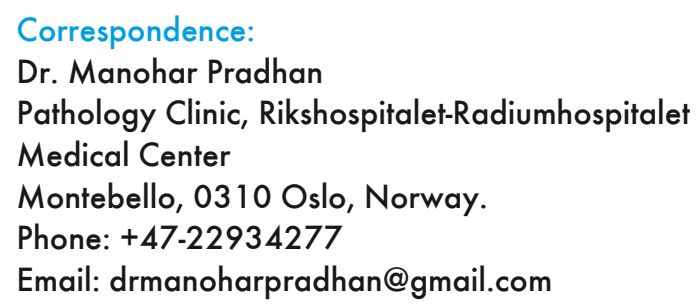


Pradhan et al. Study of Breast Lumps of 2246 Cases by Fine Needle Aspiration

\section{INTRODUCTION}

Breast cancer is one of the commonest cancers among Nepalese women and commonly presents with a lump in breast to a physician. ${ }^{1-3}$ Breast lump is caused by different benign and malignant lesions, and the management of the patients varies accordingly. Though clinical examination of the breast lump and the age of the patient can provide information about the nature of the lump, pathological examination is necessary to establish the diagnosis.

Fine-needle aspiration (FNA) cytology is a popular technique used in the evaluation of breast masses due to its advantages of being sensitive, specific, simple, economical, safe, quick and acceptable to the patients. ${ }^{4-8}$ It is commonly used in addition to clinical examination and mammography for the diagnosis of breast lesions. ${ }^{9}$

Most of the patients with breast lump undergo FNA examination initially to rule out malignancy and to find out the cause of the lump. Only a small fraction of the patients, who are clinically or radiologically or cytologically suspicious of malignancy, undergo histopathological examination. Therefore, only the analysis of FNA diagnoses can provide pathologic spectrum of causes of breast lump. The purpose was to evaluate FNA of breast lumps in a large series of patients attending a national cancer hospital in Nepal.

The aims of present study are 1) to study the spectrum of conditions/lesions causing breast lumps 2) to compare the pattern of diseases between the patients aged 30 years and below and older than 30 years 3 ) to evaluate "suspicious of malignancy" in FNA cases histologically.

\section{MATERIAL AND METHODS}

We carried out a retrospective study of 2,246 FNA cytology cases performed on breast lumps at Pathology Department of BP Koirala Memorial Cancer Hospital (BPKMCH) in Nepal between March 2000 and March 2004. We included all breast lump cases that underwent FNA procedure in the hospital, and none of the cases were excluded. Age, FNA diagnosis of all breast lump patients and the histological diagnosis of "suspicious of malignancy" cases were retrieved from the departmental records. Forty-three out of 52 cytologically suspicious cases had histopathologic diagnoses available for evaluation. The cases were divided into two groups: group I comprised 918 patients aged 30 years and younger, and group II comprised 1328 patients aged 31 years and older. This age related categorization was based on earlier reports which showed higher percentage of breast cancer among Nepalese women aged more than 30 years. ${ }^{3,10}$
All the FNAs were performed by staff pathologists utilizing a 23-gauge needle on a $10 \mathrm{ml}$ syringe. The smears from the aspirates were fixed in alcohol and stained with Papanicolaou stain; air dried smears were stained with Giemsa stain. Cytological diagnoses were made according to Orell et al. ${ }^{9}$ Repeat FNA were performed in cases of unsatisfactory and suspicious smears to evaluate better specimen. Interpretation of the smears was done by experienced pathologists at the hospital.

We followed the criteria to categorize smears as suspicious for malignancy as described. ${ }^{12}$ Briefly, cases were classified as "suspicious for malignancy" when clearly atypical features were seen in smears making pathologists almost certain that the cells came from a malignant tumor but could not reach to a firm diagnosis. Also inability for definitive diagnosis was due to hypocellularity of the smears containing cells with some degree of atypia more severe than that seen in benign lesions. Samples composed of benign cells with naked nuclei and cohesive sheets of cells with occasional cells showing distinct malignant pattern were considered as suspicious too.

Statistical analysis (Pearson Chi square test and relative risk for malignancy) was performed using SPSS (Statistical Package for the Social Sciences) version 12.1 .

\section{RESULTS}

Of all 2246 cases, 50 FNA were performed on male patients and 2196 on females. Of 50 male patients, 49 were diagnosed as gynaecomastia and 1 as malignancy. Mean age of patients at the time of diagnosis was 47 years.

The commonest cause of breast lump was fibroadenosis (975 cases, $43.4 \%$ ) followed by malignancy (348 cases, $15.5 \%)$. Only 52 cases $(2.3 \%)$ were diagnosed as suspicious of malignancy (Table 1). FNA could diagnose 20 different causes of breast lumps including lipoma, granulomatous lesion, reactive lymph node and keratinous cysts.

In group I, which comprised patients aged 30 years and younger, a malignant FNA diagnosis was made in $15(1.6 \%)$ of 918 FNA specimens and only 6 cases were diagnosed as suspicious of malignancy. In nonmalignant diagnoses, fibroadenosis (48\%) was the commonest followed by fibroadenoma (12\%) and abscess (7\%) (Table 1).

In group II, which comprised patients aged 31 years or older, malignancy was diagnosed in $333(25 \%)$ of 1328 FNA specimens. In non-malignant diagnoses, fibroadenosis $(40 \%)$ was the commonest followed by 
Pradhan et al. Study of Breast Lumps of 2246 Cases by Fine Needle Aspiration

fibroadenoma (5\%) and abscess $(4.5 \%)$ like in group one (Table 1).

Of 348 malignancies 338 were ductal carcinoma NOS, 3 mucinous carcinoma, 3 medullary carcinoma, 1 lobular carcinoma, 1 squamous cell carcinoma, 1 non-Hodgkin's lymphoma and 1 metastatic small cell carcinoma (Table 2). The distribution of 348 malignant cases by FNA showed $4 \%$ in $\leq 30$ years age group and $96 \%$ in more than 30 years of age. Forty-three of 52 cases that were diagnosed as suspicious of malignancy were evaluated later by histology and 62\% (27/43) were malignant (Table 3).

Statistical analysis showed significantly higher malignancy diagnoses $(P<0.001)$ in patients more than 30 years old compared to patients 30 years and younger. The odds of being diagnosed as having malignant tumour among the higher age group ( $>30$ years) is 21 times greater (confidence interval 12.4-35.6) compared to the younger age group ( $\leq 30$ years).
There is significantly higher incidence of fibroadenoma in patients with $<30$ years compared to $>30$ years of age $(\mathrm{P}<0.001)$.

\section{DISCUSSION}

Breast cancer, one of the commonest cancers, causes major burden of cancer related morbidity and mortality worldwide among women and is also one of the leading cancers in Nepal. ${ }^{1,2}$ Breast lump is the commonest manifestation of breast cancer. ${ }^{3,13}$ Woman can examine her own breasts and detect a lump and thus can visit a doctor at an early stage of the disease with possibility of early detection and cure. FNA, as an initial procedure to determine whether the lesion is cancer or not, is quick, simple and easy, and it can be done on outpatients basis. Thus, only FNA examination can provide information about the spectrum of causes of breast lumps since most of the cases with benign diagnoses do not undergo histological examination.

Table 1. Fine-needle (FNA) diagnoses of group I (patients aged 30 years or younger) and group II (patients aged 31 years or older)

\begin{tabular}{|c|c|c|c|}
\hline Diagnosis & $\begin{array}{l}\text { Group I } \\
\text { N }\end{array}$ & $\begin{array}{l}\text { Group II } \\
\text { N }\end{array}$ & $\begin{array}{l}\text { Total } \\
\text { N }\end{array}$ \\
\hline Malignancy & $15(1.63 \%)$ & $333(25.08 \%)$ & $348(15.49 \%)$ \\
\hline Suspicious of malignancy & $6(0.65 \%)$ & $46(3.46 \%)$ & $52(2.32 \%)$ \\
\hline Atypical hyperplasia & $2(0.22 \%)$ & $4(0.30 \%)$ & $6(0.27 \%)$ \\
\hline Fibroadenosis & $444(48.37 \%)$ & $531(39.98 \%)$ & $975(43.41 \%)$ \\
\hline Normal breast tissue & $111(12.09 \%)$ & $128(9.64 \%)$ & $239(10.64 \%)$ \\
\hline Fibroadenoma & $113(12.31 \%)$ & $67(5.05 \%)$ & $180(8.01 \%)$ \\
\hline Abscess & $66(7.19 \%)$ & $60(4.52 \%)$ & $126(5.61 \%)$ \\
\hline Fibrocystic change & $41(4.47 \%)$ & $55(4.14 \%)$ & $96(4.27 \%)$ \\
\hline Lactational change & $32(3.49 \%)$ & $5(0.38 \%)$ & $37(1.65 \%)$ \\
\hline Gynaecomastia & $23(2.51 \%)$ & $26(1.96 \%)$ & $49(2.18 \%)$ \\
\hline Mastitis & $31(3.38 \%)$ & $19(1.43 \%)$ & $50(2.23 \%)$ \\
\hline Benign cystic lesion & $6(0.65 \%)$ & $25(1.88 \%)$ & $31(1.38 \%)$ \\
\hline Duct ectasia & $6(0.65 \%)$ & $8(0.60 \%)$ & $14(0.62 \%)$ \\
\hline Galactocoele & $13(1.42 \%)$ & $3(0.23 \%)$ & $16(0.71 \%)$ \\
\hline Lipoma & $2(0.22 \%)$ & $5(0.38 \%)$ & $7(0.31 \%)$ \\
\hline Granulomatous lesion & $4(0.44 \%)$ & $5(0.38 \%)$ & $9(0.40 \%)$ \\
\hline Reactive lymph node & $2(0.22 \%)$ & $2(0.15 \%)$ & $4(0.18 \%)$ \\
\hline Phylloides tumor & $1(0.11 \%)$ & $3(0.23 \%)$ & $4(0.18 \%)$ \\
\hline Keratinous cyst & $0(0.00 \%)$ & $2(0.15 \%)$ & $2(0.09 \%)$ \\
\hline \multirow[t]{2}{*}{ Filariasis } & $0(0.00 \%)$ & $1(0.08 \%)$ & $1(0.04 \%)$ \\
\hline & 918 & 1328 & 2246 \\
\hline
\end{tabular}


Pradhan et al. Study of Breast Lumps of 2246 Cases by Fine Needle Aspiration

Table 2. FNA diagnoses of malignant cases.

\begin{tabular}{lc}
\hline FNA diagnoses & $\mathbf{N}$ \\
\hline Ductal carcinoma & $338(97.13)$ \\
Mucinous carcinoma & $3(0.86 \%)$ \\
Medullary carcinoma & $3(0.86 \%)$ \\
Lobular carcinoma & $1(0.29 \%)$ \\
Non-Hodgkin's lymphoma & $1(0.29 \%)$ \\
Squamous cell carcinoma & $1(0.29 \%)$ \\
Metastatic small cell carcinoma & $1(0.29 \%)$ \\
\hline Total & $348(100 \%)$ \\
\hline
\end{tabular}

Table 3. Subsequent histopathological diagnoses of suspicious cases in FNA

\begin{tabular}{lc}
\hline Histopathology diagnoses & N \\
\hline Malignant & $23(53.49 \%)$ \\
Infiltrating ductal carcinoma NOS & $2(4.65 \%)$ \\
Infiltrating lobular carcinoma & $2(4.65 \%)$ \\
Mucinous carcinoma & \\
Benign & $6(13.95 \%)$ \\
Adenosis & $5(11.63 \%)$ \\
Fibroadenoma & $4(9.30 \%)$ \\
Lactational change & $1(2.33 \%)$ \\
Gynaecomastia & $43(100 \%)$ \\
\hline Total & \\
\hline
\end{tabular}

As a general rule, all cases positive for malignancy in FNA should be evaluated by histology (gold standard for the diagnosis of cancer) to confirm the diagnosis as far as possible. However, FNA has been reported to be highly specific ( $>98 \%$ ) and sensitive ( $\geq 85 \%$ ) method in diagnosis of breast cancer. ${ }^{8,14}$ FNA is quick, easy and reliable for identifying cases needing for further evaluation in suspected breast cancer. It is low cost procedure and can be done on outpatient basis without requiring hospital stay. Therefore the procedure is especially useful in countries with limited resources like Nepal. In our hospital, cases of breast cancer diagnosed by FNA undergo either lumpectomy or mastectomy with or without neoadjuvant chemotherapy depending on stage of the disease. Thus, we decided only to include suspicious of malignancy cases for histopathological evaluation.

In this study, we have examined 2246 patients with breast lumps who underwent FNA procedure over a period of four years and analyzed for spectrum of lesions causing breast lumps in context of Nepal. There was significantly higher incidence of cancer in women older than 30 years of age compared to women 30 years and younger $(\mathrm{P}<0.001)$. The incidence in present study is lower compared to report by Ariga et al who found $51 \%$ of breast mass in patients aged 40 years and younger and $74 \%$ of breast lump of patients over 40 years to be malignant in 1158 patients. ${ }^{8}$ This variation could be due to difference in the population studied. Among the subtypes, ductal carcinoma was the most common accounting $95 \%$ of all breast malignancies similar to a report by Sayami et al among Nepalese women. ${ }^{3}$ Moreover, the distribution of malignancy in present study $(4 \%)$ is also similar to reports by Sayami et al $(2.5 \%)$ for age groups, 30 years and below and above 30 years of age (present study: $96 \%$ and Sayami et al $97.5 \%) .{ }^{3}$ All these findings point out the necessity of investigation in all patients with breast lumps to rule out malignancy especially women above 30 years.

In our series, $63 \%$ of the suspicious FNA cases were later diagnosed as malignancy in histology. Seventy-five percent of all the patients reported as suspicious for malignancy in FNA were later diagnosed as malignant in histopathology in an earlier report. ${ }^{15}$ Patients diagnosed as suspicious of malignancy in FNA should undergo histopathological examination for confirmation of diagnosis. We had only $2 \%$ of the cases diagnosed as suspicious which is lesser than published series in which $3-9 \%$ of the cases were diagnosed as suspicious malignant. $8,15,16$ In our institute, the aspiration procedure is performed by experienced pathologists and the procedure is repeated for inadequate smears as suggested by Berner et al. ${ }^{17}$ This might be the cause for the low percentage of suspicious cases in present series and high yield of diagnosis. Also, Wu et al have compared 200 FNA and found significantly higher diagnostic yield for FNAs performed by cytopathologists compared to FNAs performed by clinicians. ${ }^{18}$

Thirty seven percent of the suspicious cases were diagnosed as benign diseases in histopathology much higher than a report by Ishikawa et al with just $5 \%$ of benign lesions among suspicious cases. ${ }^{19}$ This indicates the presence of atypical looking cells in FNA in some of benign lesions which are difficult to distinguish from malignant cells. Therefore, when atypical looking cells in the smears which do not fulfill criteria for diagnosis of malignancy are seen, it is useful to categorize it as suspicious and to advise biopsy in such cases for further evaluation of patients avoiding over or under diagnoses.

In present series, we have diagnosed rare conditions in breast such like filariasis (by demonstrating microfilariae), keratinous cyst, granulomatous lesions and reactive lymph node in breast. This emphasizes that rare conditions also need to be considered while evaluating FNA specimens. 
Pradhan et al. Study of Breast Lumps of 2246 Cases by Fine Needle Aspiration

The most frequent lesion in the breast was found to be fibroadenosis followed by malignancy. Fibroadenoma, abscess and fibrocystic changes were among the other common causes of breast lumps. In the patients at or below 30 years of age fibroadenosis is the commonest cause, followed by fibroadenoma and abscess. Above 30 years the commonest cause was fibroadenosis followed by the malignancy, fibroadenoma and fibrocystic change. This result showed that the cancer of the breast is one of the commonest causes of breast mass in Nepalese women needing attention.

Fibroadenoma, a benign tumor of the breast, was significantly higher in patients at or below 30 years of age similar to a previously published report. ${ }^{20}$ In present study, ductal carcinoma was most common tumor in age group higher than 30 years whereas fibroadenoma was most frequent tumor in patients at or below 30 years.

\section{CONCLUSION}

Breast cancer is one of the commonest causes of breast lump particularly in women and is growing public health problem in Nepal. The incidence of the cancer is higher in women above 30 years of age. Ductal carcinoma is the commonest subtype. All suspicious of malignancy cases in FNA must be evaluated by histology to confirm the diagnosis. FNA, as part of initial cost effective and reliable method of screening, is a useful tool to identify the breast lump patients needing further evaluation in countries like Nepal.

\section{REFERENCES}

1. Pradhan M, Adhikari RC, Joshi A, Sigdel B, Basnet RB, Amatya V, et al. Present Cancer Status in T. U. Teaching Hospital, Nepal. JSSN 1999;2:13-23.

2. Annual Report 2004 of BPKoirala Memorial Cancer Hospital; 2004. p. 7.

3. Sayami P, Singh BM, Singh Y, Timila R, Shrestha U, Sayami G et al. Retrospective analysis of breast cancer cases and surgical treatment in a period of ten years. JNMA 2001:40:112-9.

4. Lannin DR, Silverman JF, Walker C, Pories WJ. Costeffectiveness of fine needle biopsy of the breast. Ann Surg 1986;203:474-80.

5. Smith TJ, Safaii H, Foster EA, Reinhold RB. Accuracy and cost-effectiveness of fine needle aspiration biopsy. Am J Surg 1985;149:540-5.

6. Palombini L, Fulciniti F, Vetrani A, De RG, Di BG, Zeppa $\mathrm{P}$, et al. Fine-needle aspiration biopsies of breast masses. A critical analysis of 1956 cases in 8 years (1976-1984). Cancer 1988;61:2273-7.

7. O'Neil S, Castelli M, Gattuso P, Kluskens L, Madsen K, Aranha G. Fine-needle aspiration of 697 palpable breast lesions with histopathologic correlation. Surgery 1997;122:824-8.

8. Ariga R, Bloom K, Reddy VB, Kluskens L, Francescatti D, Dowlat $\mathrm{K}$, et al. Fine-needle aspiration of clinically suspicious palpable breast masses with histopathologic correlation. Am J Surg 2002;184:410-3.

9. Kaufman Z, Shpitz B, Shapiro M, Rona R, Lew S, Dinbar A. Triple approach in the diagnosis of dominant breast masses: combined physical examination, mammography, and fineneedle aspiration. J Surg Oncol 1994;56:254-7.

10. Khan S, Kapoor AK, Khan IU, Shrestha GB, Singh P. Prospective study of pattern of breast diseases at Nepalgunj Medical College (NGMC), Nepal. Kathmandu Univ Med J (KUMJ);2003;1:95-100
11. Orell SR, Sterrett GF, Whitaker D. Manual and Atlas of Fine Needle Aspiration Cytology. 2nd ed. Churchill Livingstone; 1992.

12. Zakhour H, Wells C, Perry NM. Diagnostic cytopathology of the breast. London: Churchill Livingstone; 1999. p. 72.

13. Parkin DM, Bray F, Ferlay J, Pisani P. Global cancer statistics, 2002. CA Cancer J Clin 2005;55:74-108.

14. Arisio R, Coccorese C, AccinelliG, Mano MP, Bordon R, Fessia L. Role of fine-needle aspiration biopsy in breast lesions: analysis of a series of 4,110 cases. Diagn Cytopathol1995;18:462-67.

15. Boerner S, Fornage BD, Singletary E, Sneige N. Ultrasoundguided fine-needle aspiration (FNA) of nonpalpable breast lesions: a review of 1885 FNA cases using the National Cancer Institute-supported recommendations on the uniform approach to breast FNA. Cancer 1999;87:19-24.

16. Sneige N. Fine-needle aspiration of the breast: a review of 1,995 cases with emphasis on diagnostic pitfalls. Diagn Cytopathol 1993;9:106-12.

17. Berner A, Davidson B, Sigstad E, Risberg B. Fine.needle aspiration cytology vs core biopsy in the diagnosis of breast lesions. Diagn Cytopathol 2003;29:106-12.

18. Wu M, Burstein DE, Yuan S, Nurse LA, Szporn AH, Zhang D, et al. A comparative Study of 200 Fine Needle Aspiration Biopsies Performed by Clinicians and Cytopathologists. The Laryngoscope 2006;116:1212-15.

19. Ishikawa T, Hamagichi $Y$, Tanabe M, Moyiyama N, Chisimo T, NakataniY et al. False-Positive and False-Negative Cases of Fine_Needle Aspiration Cytology for Palpable Breast Lesions. Breast Cancer 2007;14:388-92.

20. Cole P, Mark Elwood J, Kaplan SD. Incidence rates and risk factors of benign breast neoplasms. Am J Epidemiol 1978;108:112-20. 